\title{
BMJ Open How big is your bubble? Characteristics of self-isolating household units ('bubbles') during the COVID-19 Alert Level 4 period in New Zealand: a cross- sectional survey
}

Nethmi Kearns (D) , ${ }^{1}$ Nick Shortt, ${ }^{1}$ Ciléin Kearns, ${ }^{1}$ Allie Eathorne, ${ }^{1}$ Mark Holliday, ${ }^{1}$ Diane Mackle, ${ }^{1}$ John Martindale, ${ }^{1}$ Alex Semprini (1) , ${ }^{1,2}$ Mark Weatherall, ${ }^{1,3}$ Richard Beasley (D) , ${ }^{1,2,4}$ Irene Braithwaite (D) 1,2

To cite: Kearns N, Shortt N, Kearns $\mathrm{C}$, et al. How big is your bubble? Characteristics of self-isolating household units ('bubbles') during the COVID-19 Alert Level 4 period in New Zealand: a crosssectional survey. BMJ Open 2021;11:e042464. doi:10.1136/ bmjopen-2020-042464

- Prepublication history and supplemental material for this paper is available online. To view these files, please visit the journal online (http://dx.doi org/10.1136/bmjopen-2020042464).

Received 06 July 2020 Revised 09 December 2020 Accepted 10 January 2021

Check for updates

(C) Author(s) (or their employer(s)) 2021. Re-use permitted under CC BY-NC. No commercial re-use. See rights and permissions. Published by BMJ.

For numbered affiliations see end of article.

Correspondence to

Dr Nethmi Kearns;

nethmi.kearns@mrinz.ac.nz

\section{ABSTRACT}

Objective To characterise the self-isolating household units (bubbles) during the COVID-19 Alert Level 4 lockdown in New Zealand.

Design, setting and participants In this cross-sectional study, an online survey was distributed to a convenience sample via Facebook advertising and the Medical Research Institute of New Zealand's social media platforms and mailing list. Respondents were able to share a link to the survey via their own social media platforms and by email. Results were collected over 6 days during Alert Level 4 from respondents living in New Zealand, aged 16 years and over.

Main outcomes measures The primary outcome was the mean size of a self-isolating household unit or bubble. Secondary outcomes included the mean number of households in each bubble, the proportion of bubbles containing essential workers and/or vulnerable people, and the mean number of times the home was left each week. Results 14876 surveys were included in the analysis. The mean (SD) bubble size was 3.58 (4.63) people, with mean (SD) number of households $1.26(0.77)$. The proportion of bubbles containing one or more essential workers, or one or more vulnerable persons was $45.3 \%$ and $42.1 \%$, respectively. The mean number of times individual bubble members left their home in the previous week was 12.9 (12.4). Bubbles that contained at least one vulnerable individual had fewer outings over the previous week compared with bubbles that did not contain a vulnerable person. The bubble sizes were similar by respondent ethnicity.

Conclusion In this New Zealand convenience sample, bubble sizes were small, mostly limited to one household, and a high proportion contained essential workers and/or vulnerable people. Understanding these characteristics from a country which achieved a low COVID-19 infection rate may help inform public health interventions during this and future pandemics.

\section{INTRODUCTION}

The SARS-CoV-2 (COVID-19) pandemic has spread around the world infecting millions

\section{Strengths and limitations of this study}

- First known study to report characteristics of self-isolating household units during COVID-19 lockdown.

- The study rapidly gained high level information from approximately $1 \%$ of New Zealand households within a 6-hour period very close to the initiation of lockdown.

The study used a convenience sample survey predominantly recruited via Facebook and therefore is vulnerable to selection bias.

of people and leaving a significant death toll in its wake. The pandemic has constituted a Public Health Emergency of International Concern, ${ }^{1}$ with New Zealand reporting its first case of COVID-19 on 26 February 2020. ${ }^{2}$ In response to the pandemic, the New Zealand government created and implemented a fourlevel COVID-19 Alert System ${ }^{3}$ that specifies public health and social measures to mitigate against the disease, as illustrated in figure 1. Restrictions placed on the public increase throughout the levels until, in the event of sustained and intensive transmission of the disease with widespread outbreaks, a Level 4 'lockdown' is imposed to stall disease progression and assist with identifying and tracing new cases.

Isolation, quarantine and lockdowns are among the oldest and most effective public health measures for controlling communicable disease outbreaks. ${ }^{4}{ }^{5}$ Lockdowns refer to a community-wide containment strategy that is applied to an entire community, city or region. They are designed to reduce personal movement and interactions. Many countries have employed similar 


\begin{tabular}{|c|c|c|}
\hline $\begin{array}{c}\text { Level } 1 \\
\text { Prepare }\end{array}$ & $\begin{array}{l}\text { - The disease is contained in New Zealand } \\
\text { - COVID-19 is uncontrolled overseas } \\
\text { - Isolated household transmission could be } \\
\text { occurring in New Zealand }\end{array}$ & $\begin{array}{l}\text { - } \text { Border restrictions are in place } \\
\text { - No physical distancing is required } \\
\text { - Nools and workplaces open } \\
\text { - Intensive testing and contact-tracing } \\
\text { - Self-isolation and quarantine required }\end{array}$ \\
\hline $\begin{array}{c}\text { Level } 2 \\
\text { Reduce }\end{array}$ & $\begin{array}{l}\text { - The disease is contained, but there is a risk } \\
\text { of community transmission } \\
\text { - Household transmission could be occurring } \\
\text { - Single or isolated outbreaks }\end{array}$ & $\begin{array}{l}\text { - Businesses, work places, educational facilities and public venues open with physical } \\
\text { distancing measures and certain restrictions number of patrons } \\
\text { - No more than } 10 \text { people at gatherings except funerals and tangihanga } \\
\text { - Hospitality businesses must keep groups of customers separated, seated, and } \\
\text { served by a single person } \\
\text { - Domestic travel is allowed }\end{array}$ \\
\hline $\begin{array}{c}\text { Level } 3 \\
\text { Restrict }\end{array}$ & $\begin{array}{l}\text { - High risk the disease is not maintained } \\
\text { - Community transmission may be happening } \\
\text { controlled }\end{array}$ & $\begin{array}{l}\text { - Stay at home, other than for essential personal movement, and going to } \\
\text { work/school. } \\
\text { - Stay in extended bubble, which can now include close family or caregivers. } \\
\text { - Schools (years } 1 \text { to } 10 \text { ) and Early Childhood Education centres can safely open, with } \\
\text { limited capacity } \\
\text { - Businesses can open premises, but cannot physically interact with customers } \\
\text { - Inter-regional travel is highly limited } \\
\text { - Gatherings of up to } 10 \text { people are allowed but only for wedding services, funerals } \\
\text { and tangihanga }\end{array}$ \\
\hline $\begin{array}{c}\text { Level } 4 \\
\text { Lockdown }\end{array}$ & $\begin{array}{l}\text { - Likely the disease is not contained } \\
\text { - Community transmission is occurring } \\
\text { - Widespread outbreaks and new clusters }\end{array}$ & $\begin{array}{l}\text { - Stay at home, other than for essential personal movement and doing essential } \\
\text { - } \text { - Stay in immediate household bubble } \\
\text { - Travel is severely limited } \\
\text { - All gatherings cancelled } \\
\text { - All public venues and educational facilities are closed }\end{array}$ \\
\hline
\end{tabular}

Figure 1 New Zealand COVID-19 Alert Levels. The Alert System outlines the current level of risk from COVID-19 and the restrictions that legally must be followed in New Zealand.

containment strategies, although the parameters and methods of enforcement have varied considerably. ${ }^{6}$ China implemented the first lockdown in response to COVID-19 in Wuhan on 23 January 2020, ${ }^{7}$ and many countries, ${ }^{8}$ and some states in the $\mathrm{USA}^{6}$ have done the same.

The New Zealand government implemented Alert Level 4, one of the most stringent lockdowns internationally, ${ }^{6}$ at 23:59 on Wednesday, 25 March 2020. A state of national emergency was declared and under section 70(1) (f) of the Health Act $1956,{ }^{9}$ New Zealanders were legally required to self-isolate at home. All educational facilities, public venues and business barring essential services were closed, travel was severely limited and all outdoor and indoor gatherings were banned. All individuals other than those working for essential services were instructed to stay in isolation at home unless buying groceries, exercising locally or seeking medical help. ${ }^{3}$ While the term 'isolation' refers to the separation of a person or group of people known or believed to be infected with a communicable disease, 'quarantine' is the more accurate term. 'Isolation' and 'self-isolation' have been widely used in the media and by the public. Therefore, when we refer to isolation in this paper, it is intended to mean quarantine.
The New Zealand government and public health authorities developed a public messaging campaign that reinforced the concept of 'staying in one's bubble' (figure 2).

The term 'bubble' has been widely used in the media and by the New Zealand government to describe the household unit within which an individual self-isolates. The bubble or household unit may span multiple households, for example, in shared custody or blended families. The public were urged to stay within their bubble and to avoid contact with other bubbles. Given the novelty of this concept, this study aimed to describe New Zealand bubbles and to explore relationships between bubble characteristics and bubble behaviours. These characteristics are of international interest in view of the successful public health measures including selfisolation, which resulted in elimination of COVID-19 in New Zealand ${ }^{10}$ within 8 weeks of their implementation (figure 3).

The primary objective was to determine the average size of bubbles. Secondary objectives included determining the mean number of households in each bubble, the proportion of bubbles containing essential workers and/ or vulnerable people, and the mean number of times the home was left by bubble members each week. 


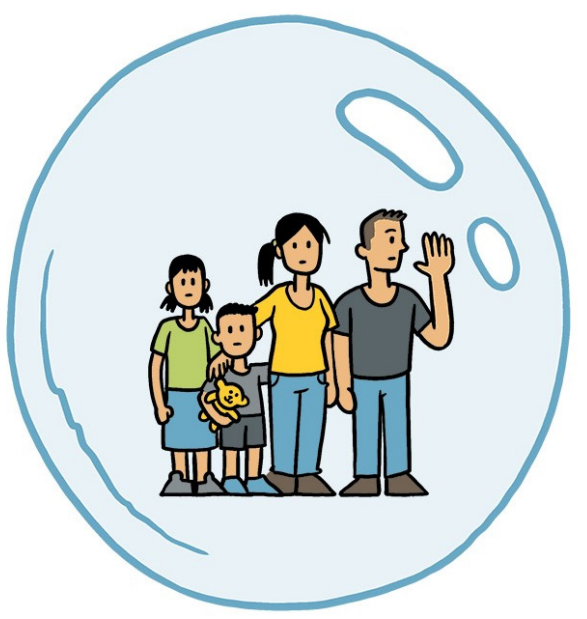

@SIOUXSIEW @XTOTL thespinoff.co.nz

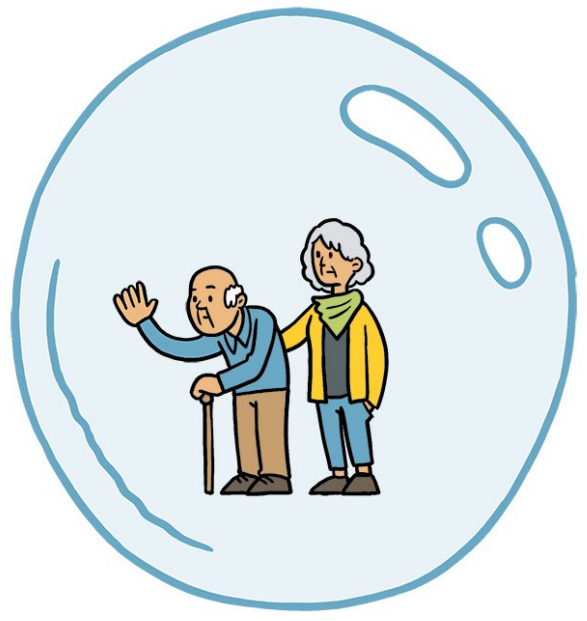

CC-BY-SA

Figure 2 The bubble. The term 'bubble' has been widely used in the media and by the New Zealand government to describe the household unit within which an individual self-isolates. Image by Morris T. Do not pop the bubble. The Spinoff. CC-BY-SA.

\section{METHODS}

\section{Study design}

This was a cross-sectional study using an online survey created on REDCap ${ }^{11}$ (online supplemental file 1). The respondents answered questions relating to their bubble and each completed survey represented a single bubble. The questions included the number of people and households within the bubble, whether any members were essential workers or vulnerable people according to Ministry of Health guidelines, ${ }^{12} 13$ and the total number of times individuals within their bubbles left their home. They also answered questions about themselves (age, ethnicity, whether they were an essential worker or vulnerable, and how often they had left their home for exercise, shopping, essential work and any other reason). The survey initially required respondents to provide their address to identify duplicates but following feedback this was changed to just suburb and postcode.

A survey was included in the analysis if the participant answered all the following compulsory questions:

1. How many people (including yourself) are in the bubble?

2. How many households are in your bubble?

3. Do any people in your bubble work in an essential service?

4. Are any people in your bubble vulnerable to COVID- $19^{8}$ ?

Ethnicity was collected using the standard ethnicity question for the New Zealand health and disability sector. $^{14}$

Respondents were also given the option of providing information about each of the remaining members of

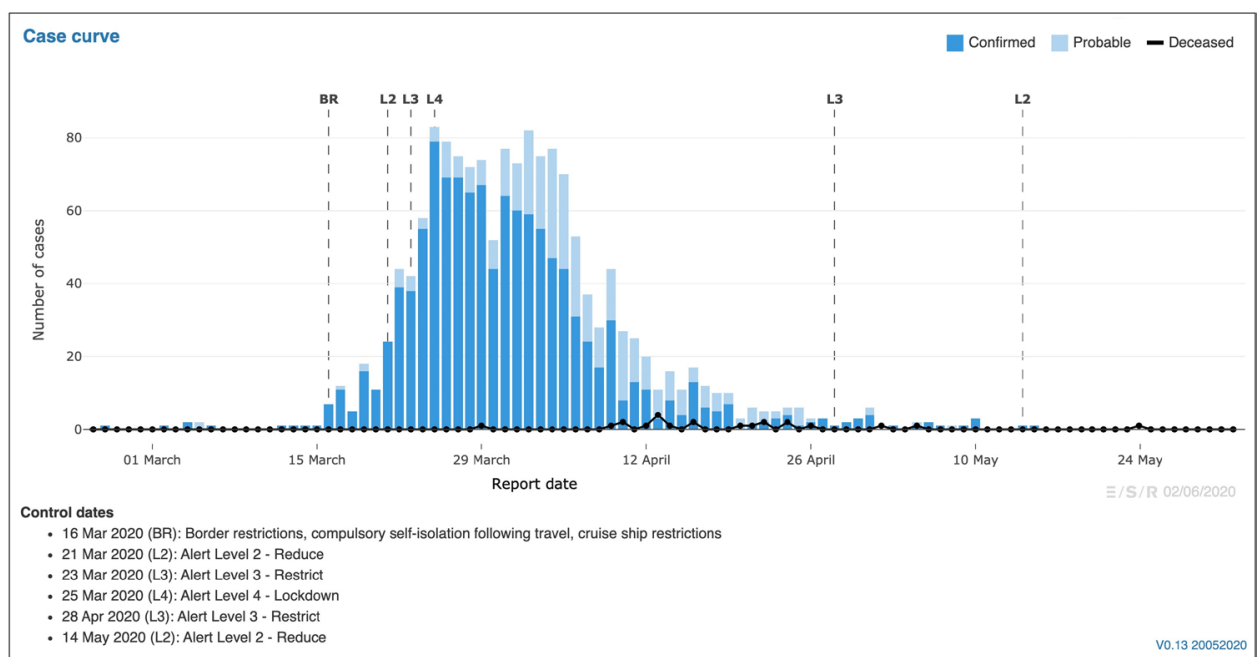

Figure 3 COVID-19 Epidemic Curve in New Zealand. COVID-19 epidemic curve for the period 24 February 2020-8 June 2020, with dates for restrictions and Alert Levels in place. Surveillance data provided by Institute of Environmental Science and Research (ESR), funded by the Ministry of Health, New Zealand. Dashboard developed by EPI-interactive. 
their bubbles: age, ethnicity, whether they were an essential worker or vulnerable, and how often they had left the home. However, due to capacity issues with the servers hosting our instance of REDCap, the majority of respondents were unable to fill in information about their household members. Therefore, these data are not included or reported in this study.

\section{Setting}

Online social media platforms and email were used to share links to the online REDCap survey. A Facebook advertisement was used to promote the survey at random to Facebook users in New Zealand aged 16 years or older, over a 72-hour period.

A link to the survey was also posted on the Medical Research Institute of New Zealand (MRINZ) website, Facebook page and Twitter account. The participant database for MRINZ was also emailed with a link to the online survey. For all approaches, participants were able to share a link to the survey via their own social media platforms and by email. The period of data collection was during Alert Level 4, from 9 to 14 April 2020.

\section{Participants}

Individuals were eligible if they were a resident in New Zealand and aged 16 years and over.

\section{Ethics approval}

Consent was implied by completion of the survey. As this study was a minimal risk observational study and involved members of the general public recruited other than in their capacity as consumers of health and disability services, it did not require approval from an ethics committee as per Section 3 of the Standard Operating Procedures for the Health and Disability Ethics Committees in New Zealand. ${ }^{15}$

\section{Patient and public involvement}

Patients or the public were not involved in the design, or conduct, or reporting or dissemination plans of our research. However, after the feedback of participants on concerns over privacy, we removed the question relating to full address details.

\section{Data management}

All data were entered directly by the participant into the REDCap database, hosted and supported by the MRINZ. REDCap is a secure, HIPAA (US Health Insurance Portability and Accountability Act 1996) compliant web-based application. ${ }^{11}$ Data were accessible only to a limited number of trained study investigators. For surveys where addresses were provided, duplicates were removed manually.

\section{Bias}

This was a convenience sample, reliant on advertising and participants sharing the survey online.

\section{Study size}

We wished to achieve a 5\% margin of error for single responses and this required 385 complete responses. ${ }^{16}$ As this was cluster sampling (a sample of 'bubbles'), with unknown cluster distribution and intraclass correlation, and undertaken on social media without a fully random sampling methodology, the design effect for cluster sampling was conservatively taken into account by increasing the sample size by $50 \%$, aiming to achieve 580 responses about individual bubbles. There was no upper limit to the sample being sought.

\section{Statistical methods}

Data descriptions were by simple counts and proportions and data descriptors: mean and SD, median and $25 \%$ and $75 \%$ quantiles as the IQR and minimum to maximum. T-tests were also used to compare bubble size and household number per bubble. The association between ethnicity and bubble size and household number per bubble used analysis of variance with European ethnicity as the reference level. The primary comparison of interest was with Māori, the Indigenous Peoples of New Zealand, who had markedly higher mortality rates during the 1918 influenza pandemic. ${ }^{17}$ The association between rate of leaving, in relation to bubble size, the bubble, and at least one essential or at least one vulnerable person in the bubble was by Poisson regression with an offset for bubble size. Any survey that included an answer for the primary outcome variable were included in the analysis. Data were not imputed for where consequent questions are unanswered. SAS V.9.4 was used.

\section{RESULTS}

A total of 18788 surveys were answered across New Zealand and 14876 complete surveys were included in the analysis (figure 4).

The number of responses varied by region and is illustrated in Figure 5.

\section{Respondent characteristics}

The majority of survey respondents were female and of European descent (table 1). The mean (SD) age of respondents was 45.4 (14.6) years. Respondents who were essential workers and vulnerable individuals were contained within $26.1 \%$ and $22.4 \%$ of bubbles, respectively. The most common reason the respondents left their home was for exercise; mean (SD) number of times per week 4.27 (4.83).

\section{Bubble characteristics}

Bubbles contained a mean (SD) of 3.58 (4.63) people and $1.26(0.77)$ households (table 1$)$. The majority of bubbles contained only one household $(80 \%)$, with only 64 bubbles containing five or more households. The proportion of bubbles that contained at least one essential worker or at least one vulnerable individual was $45.3 \%$ and $42.1 \%$, respectively. Only $29.7 \%$ of 


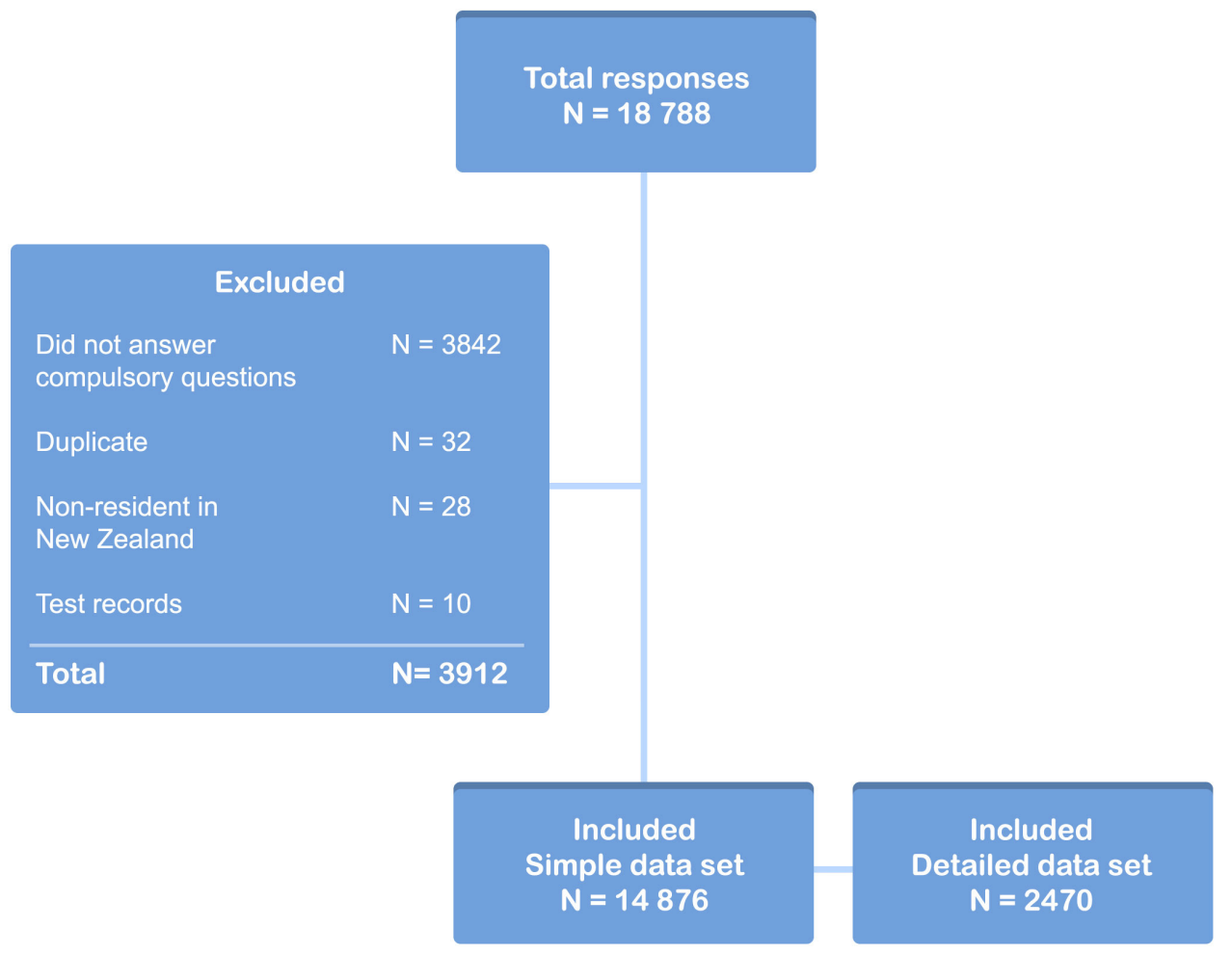

Figure 4 Survey responses. Flow diagram of included and excluded survey responses with reasons.

bubbles had neither an essential worker nor vulnerable person. Individual bubble members left their home a mean (SD) 12.9 (12.4) times in the previous week, most often for exercise. There was minimal difference in the bubble size across the regions (range 3.5-3.8 excluding the Chatham Islands which had one bubble of four people).

\section{Ethnicities and bubble size}

Bubbles with Māori and Pacific respondents had a larger bubble size, and the difference was significant when comparing Māori respondents to Europeans (table 2). Similar results were seen when comparing the number of households per bubble by ethnicity. Bubbles in which the respondent was Māori contained a mean (95\% CI) 0.09 (0.04 to 0.14) more households compared with bubbles in which the respondent was European.

\section{Bubbles with essential workers and/or vulnerable members}

Bubbles that contained at least one essential worker had a mean (SD) 14.2 (13.2) leaving episodes in the preceding week compared with bubbles with no essential workers which had 11.8 (11.5) leaving episodes; relative rate 1.03 (95\% CI 1.02 to 1.04 ), $\mathrm{p}<0.001$.

Bubbles that contained at least one vulnerable individual had an approximately $25 \%$ lower rate of leaving (relative rate 0.75 (95\% CI 0.74 to 0.75$), \mathrm{p}<0.001)$ in the previous week compared with bubbles that contained no vulnerable individuals.

\section{DISCUSSION}

In this survey, isolation bubbles were generally small, containing three to four people, and mostly one household. About $70 \%$ of bubbles had an essential worker and/ or vulnerable person. Bubble sizes and the mean number of households in the bubbles of Māori respondents were slightly larger than that of European respondents. Bubble members left the home approximately two times per day in total. Bubbles containing a vulnerable person had fewer leaving events than bubbles that did not contain a vulnerable person.

In New Zealand, the Level 4 lockdown between 25 March and 28 April 2020 had a marked effect in terms of reducing the COVID-19 infection rate towards achieving a goal of elimination (figure 3 ). It is not possible to determine from our survey the specific contribution of selfisolation to this outcome, relative to other public health measures including border closures, extensive testing and contact tracing. However, it is reasonable to assume that when part of such a multifaceted public health strategy, self-isolation within 'bubbles' with the characteristics identified in this survey contributed to the reduction in cases of COVID-19 in New Zealand.

It is also challenging to determine from our survey the specific influence that the political and social environment may have had on the characteristics observed. New Zealand is a social democracy, and there was widespread support for the Prime Minister and Director General of Health, who based their policies on advice received from cross party parliamentary and technical advisory committees, and communicated to the public on a daily basis. ${ }^{10}$ 


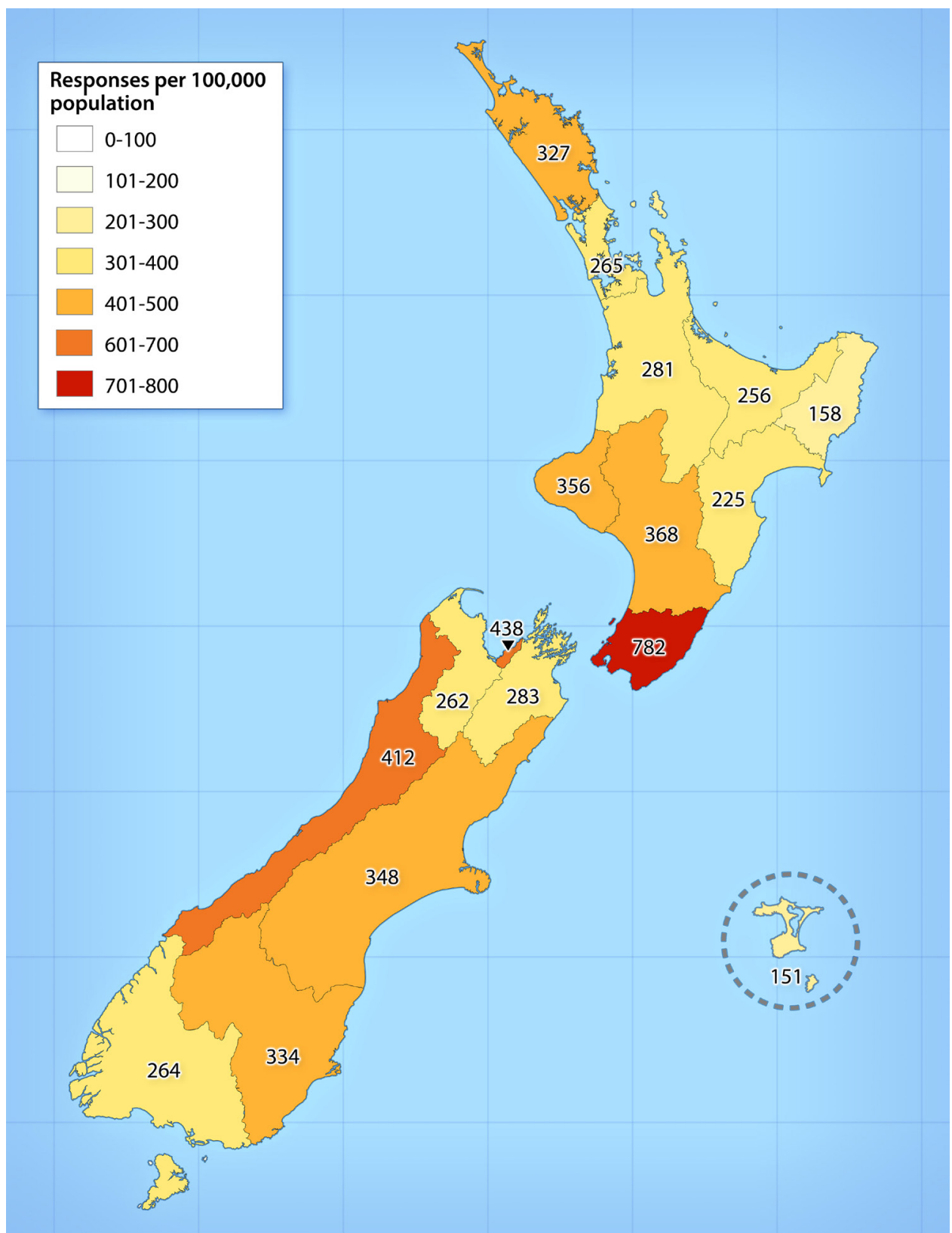

Figure 5 Regional distribution of survey responses. Regional distribution of included survey responses per 100000 population in New Zealand.

This contrasts with the more autocratic implementation of severe lockdown strictly enforced in China, ${ }^{18}$ and the fragmented and chaotic political and public health situation in the USA. ${ }^{19}$

To our knowledge, this is the first study to provide information on the self-isolating household units and the composition of households during lockdown, adding to the knowledge gap of an intervention that is currently used worldwide. We rapidly gained high level information from approximately $1 \%$ of New Zealand households within a 6-hour period very close to the initiation of lockdown, using the strength of social media and a current patient database. It also provided an opportunity for participants to engage and learn about the lockdown itself, and to actively consider behaviours that might cause public health risk to themselves and others.

The number of individuals in each bubble is of importance given how COVID-19 is transmitted. Droplet transmission among individuals with close contact can be higher in overcrowded houses and in household units with a larger number of individuals. Having blanket regulations about isolation may not have the desired effect if large numbers of individuals isolate together. The living arrangements and household composition can vary between, as well as within, countries. Pakistan and the Philippines have also been in lockdown with an anticipated average household size of 6.8 and 4.2 individuals, respectively, ${ }^{20}$ larger than the New Zealand census 


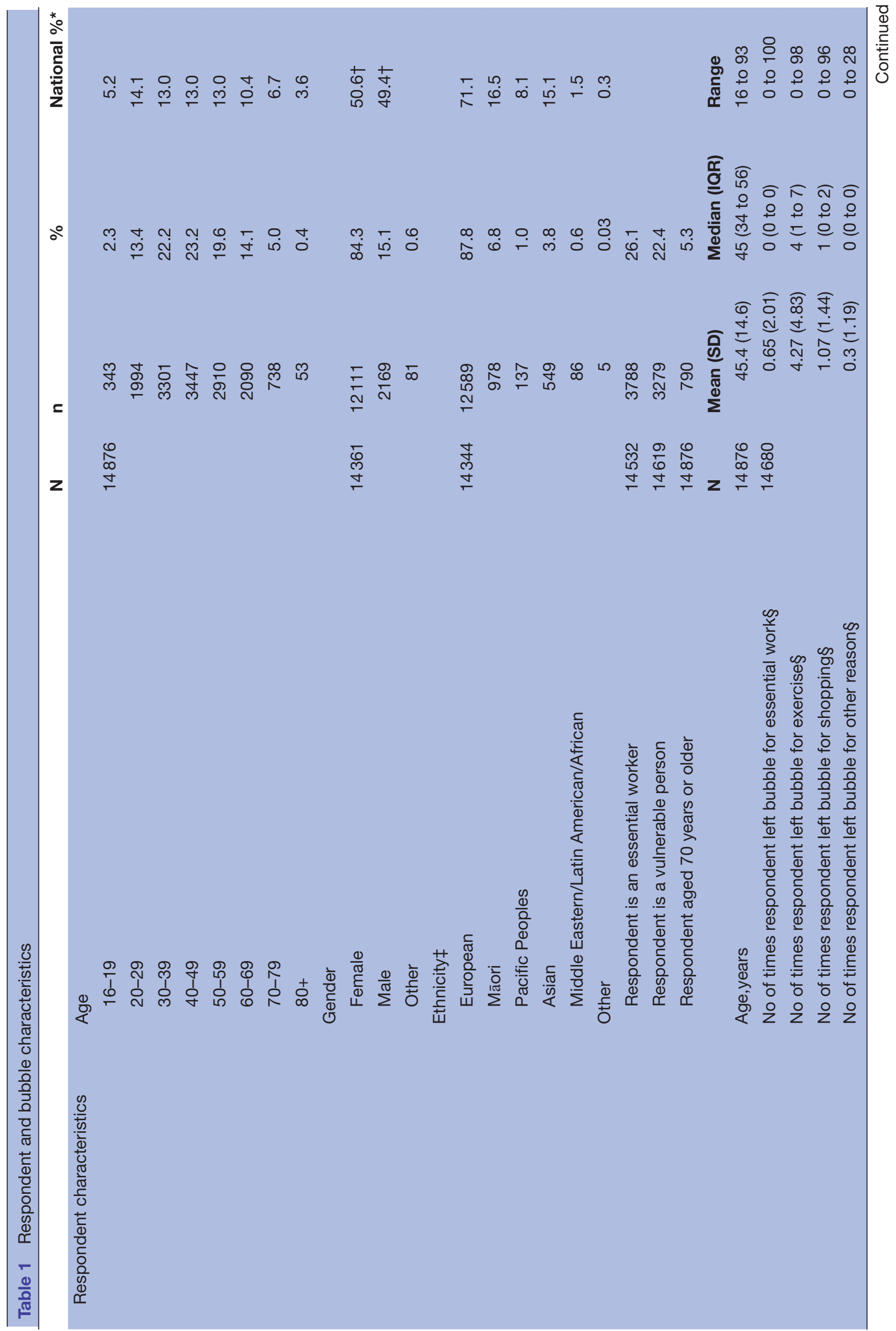




\begin{tabular}{|c|c|c|}
\hline Ethnicity (N) & $\begin{array}{l}\text { Mean bubble size } \\
(95 \% \mathrm{Cl})\end{array}$ & $\begin{array}{l}\text { Difference from } \\
\text { European }(95 \% \mathrm{Cl})\end{array}$ \\
\hline $\begin{array}{l}\text { European } \\
\text { (12589) }\end{array}$ & 3.54 (3.46 to 3.62$)$ & NA \\
\hline Māori (978) & 4.06 (3.77 to 4.36$)$ & $0.52^{*}(0.22$ to 0.83$)$ \\
\hline $\begin{array}{l}\text { Pacific Peoples } \\
\text { (137) }\end{array}$ & 4.06 (3.27 to 4.85$)$ & $0.52(-0.27$ to 1.31$)$ \\
\hline Asian (549) & 3.72 (3.33 to 4.11$)$ & $0.18(-0.22$ to 0.58$)$ \\
\hline $\begin{array}{l}\text { Middle Eastern/ } \\
\text { Latin American/ } \\
\text { African (86) }\end{array}$ & 3.19 (2.19 to 4.18$)$ & $-0.35(-1.35$ to 0.65$)$ \\
\hline Other (5) & $3.60(-0.52$ to 7.72$)$ & $0.06(-4.06$ to 4.19$)$ \\
\hline
\end{tabular}

${ }^{*} \mathrm{p}<0.05$.

average of 2.7 individuals ${ }^{21}$ and the reported bubble size in our study of 3.6 members. Our sample bubble size may be slightly larger due to the convenience sampling methodology, temporary changes in living situations in view of lockdown or inclusion of other households to the bubble. Regardless, the small bubble size of three to four individuals will have a reduced scope for transmission of COVID-19 within the household.

Nearly half of the bubbles contained one or more essential workers. It is surprising that the number of times individuals left their home during the previous week was not higher in bubbles that contained essential workers compared with bubbles that did not. It is possible that many essential workers who responded to this survey were able to complete their work role from home or on an 'oncall' basis. It may also be that essential workers combined leaving their home for work and outings such as shopping, which members of bubbles with no essential workers had to leave their home for. Reassuringly, while approximately $40 \%$ of bubbles contained at least one vulnerable person, bubbles that contained a vulnerable person had fewer instances of members leaving their home during the previous week.

The mean number of times bubble members left their home in this sample was 12.9 times per week. The risk of exposure associated with such activity is likely to vary markedly depending on the purpose, for example, exercising locally with physical distancing, which was the most common reason for leaving home, is likely to represent a far lower risk than shopping or 'essential work'. While this change in movement only reflects weeks 2 and 3 of lockdown, mobility data across New Zealand suggest that this trend was consistent across the entire lockdown period, with New Zealanders spending a larger proportion of time in their places of residence compared with before lockdown (online supplemental figure 1).

New Zealand's indigenous population, Te Māori, have historically fared poorly in pandemic respiratory illnesses compared with NZ Europeans. ${ }^{22} 23$ Māori suffered an overall death rate of about eight times that of $\mathrm{NZ}$ 
Europeans in the 1918 influenza pandemic ${ }^{17}$ and were fivefold more likely to be admitted to hospital ${ }^{23}$ and 2.6fold more likely to die $^{22}$ than NZ Europeans in the 2009 H1N1 pandemic. There has been concern that ongoing inequities in New Zealand could result in increased risk of infection for Māori, greater risk of negative COVID-19 health impacts, and worsening of the current inequities in access to high-quality healthcare for Māori negatively impacting on Māori health outcomes from both COVID-19 and non-COVID-19 conditions. ${ }^{24}$ We had considered that as Māori are already affected by household overcrowding, ${ }^{25}$ bubbles containing individuals of Māori ethnicity might be larger and incorporate more households, potentially increasing transmission within bubbles despite a lockdown.

Currently, the prevalence of COVID-19 on Māori has been lower than in European New Zealanders, which has been attributed to the higher rate of European New Zealanders returning with COVID-19 infection from overseas prior to lockdown. ${ }^{26}$ Of concern, this survey observed that bubbles that contained individuals of Māori ethnicity were substantially larger or contained more households than those that contained Europeans, suggesting that Māori may be at greater risk in the situation of a more widespread community transmission of COVID-19.

As with all surveys of this nature, there are methodological limitations that need to be considered. This was a convenience sample survey predominantly recruited via Facebook and vulnerable to selection bias. Despite the number of roughly equal male $(46.7 \%)$ and female $(53.3 \%)$ Facebook users in New Zealand ${ }^{27}$ and gender not being a criteria for targeted advertising of the survey, female respondents were over-represented in this survey, suggesting perhaps greater responsiveness to online survey-based research. In a previous study we conducted using Facebook for advertising, we had greater participation from female than male ${ }^{28}$; a trend seen in other online survey responses as well. ${ }^{27}$ The number of adults aged 70 and older was also small compared with the New Zealand population, likely reflecting the use of social media for the survey.

New Zealand however has a high internet penetration rate of $93 \%,{ }^{29}$ and in March 2020, Facebook had 3.48 million ${ }^{30}$ users aged $>16$ years in New Zealand, up to $92 \%$ of the New Zealand population at this time. As the study was intended for those 16 years and above, distribution of the survey via Facebook offered the potential to reach most of the population of interest. Facebook has previously been proven to be an effective form of sampling in health research recruitment where it produced representative data for a population, while having additional benefits of supporting the inclusion of hard-to-reach and younger populations. ${ }^{31} 32$ This methodology of conducting online surveys via Facebook, however, may not be as successful in areas with low internet penetration or low uptake of social media such as Facebook.

We initially collected full addresses from respondents in order to remove duplicates if another member of the same household answered the survey. However, following feedback from the respondents, we changed the survey to only collect the suburb and postcode. Consequently, the ability to detect further duplicates was lost, although it is unlikely to lead to major bias, as duplicates were uncommon (37 duplicates $(3.7 \%)$ in the first 1000 responses). In the interest of obtaining complete responses and focusing on our primary outcome variable, we kept the survey short. The response rate from nonEuropeans is less than we would expect given the proportion within the New Zealand population. ${ }^{33}$ We did not ask specifics about essential worker roles or vulnerabilities contained within the bubbles. Approximately $40 \%$ of bubbles contained one or more vulnerable people, potentially lower than might be expected given the burden of chronic disease in New Zealand. ${ }^{34}$ The responses may also have been affected by social desirability bias, where the answers reflect expected behaviour instead of actual behaviour. The New Zealand government's COVID-19 response was widely visible and well disseminated with a broad presence across analogue and digital media, thereby potentially inflating or deflating individuals' responses (eg, under-reporting the times the bubble was left, or the number of households per bubble). We mitigated this by not collecting identifiable information and the survey was completed by the responder in their own time, without the presence of an investigator, eliminating the possibility of coercion or fear of judgement.

The Alert Level 4 lockdown in New Zealand has succeeded in limiting the spread of COVID-19, despite an initial trajectory similar to other countries in Western Europe and North America. ${ }^{35}$ As a result, the reported confirmed cases of 433 per million in New Zealand is substantially less than that of the UK (25851 per million) and the USA (45815 per million) ${ }^{36}$ (as of 10 December 2020). The requirement for self-isolation within bubbles resulted in a small number of individuals and households per bubble, in combination with reduced movement out of the bubble, especially in bubbles that contained vulnerable persons. While the bubbles, in conjunction with other public health measures in New Zealand, appear to have had the desired effect, to date, additional knowledge of the lockdown units and their implementation may assist in identifying other levers that can be used to shape further public health interventions if the rapid mitigation of COVID-19 cases is not achieved.

\section{Author affiliations \\ ${ }^{1}$ Medical Research Institute of New Zealand, Wellington, New Zealand \\ ${ }^{2}$ School of Biological Sciences, Victoria University of Wellington, Wellington, New Zealand \\ ${ }^{3}$ Department of Medicine, University of Otago Wellington, Wellington, New Zealand ${ }^{4}$ Department of Respiratory Medicine, Capital and Coast Distirct Health Board, Wellington, New Zealand}

Contributors Substantial contributions to the conception of the work: RB, IB. Substantial contributions to the design of the work: NK, IB, NS, CK, AS, MH, JM, DM. Substantial contributions to the acquisition of data for the work: NS, CK. Substantial contributions the analysis of the work: AE, MW. Substantial contributions to the interpretation of data for the work: NK, IB, CK. Drafting the work: NK, IB. Revising 
the work critically for important intellectual content: NK, NS, CK, AE, MH, DM, JM, $A S, M W, R B, I B$. Final approval of the version to be published: NK, NS, CK, AE, MH, $\mathrm{DM}, \mathrm{JM}, \mathrm{AS}, \mathrm{MW}, \mathrm{RB}, \mathrm{IB}$. Agreement to be accountable for all aspects of the work in ensuring that questions related to the accuracy or integrity of any part of the work are appropriately investigated and resolved: NK, NS, CK, AE, MH, DM, JM, AS, MW, $\mathrm{RB}, \mathrm{IB}$.

Funding The Medical Research Institute of New Zealand receives Independent Research Organisation funding from the Health Research Council of New Zealand (IR0 grant [18/002]).

Map disclaimer The depiction of boundaries on the map(s) in this article does not imply the expression of any opinion whatsoever on the part of BMJ (or any member of its group) concerning the legal status of any country, territory, jurisdiction or area or of its authorities. The map(s) are provided without any warranty of any kind, either express or implied.

Competing interests None declared.

Patient consent for publication Not required.

Ethics approval As this study was a minimal risk observational study and involved members of the general public recruited other than in their capacity as consumers of health and disability services, it did not require approval from an ethics committee as per Section 3 of the Standard Operating Procedures for the Health and Disability Ethics Committees in New Zealand.

Provenance and peer review Not commissioned; externally peer reviewed.

Data availability statement Data are available upon reasonable request. Extra data is available by emailing irene.braithwaite@mrinz.ac.nz.

Supplemental material This content has been supplied by the author(s). It has not been vetted by BMJ Publishing Group Limited (BMJ) and may not have been peer-reviewed. Any opinions or recommendations discussed are solely those of the author(s) and are not endorsed by BMJ. BMJ disclaims all liability and responsibility arising from any reliance placed on the content. Where the content includes any translated material, BMJ does not warrant the accuracy and reliability of the translations (including but not limited to local regulations, clinical guidelines, terminology, drug names and drug dosages), and is not responsible for any error and/or omissions arising from translation and adaptation or otherwise.

Open access This is an open access article distributed in accordance with the Creative Commons Attribution Non Commercial (CC BY-NC 4.0) license, which permits others to distribute, remix, adapt, build upon this work non-commercially, and license their derivative works on different terms, provided the original work is properly cited, appropriate credit is given, any changes made indicated, and the use is non-commercial. See: http://creativecommons.org/licenses/by-nc/4.0/.

\section{ORCID iDs}

Nethmi Kearns http://orcid.org/0000-0002-3188-991X

Alex Semprini http://orcid.org/0000-0003-0949-0555

Richard Beasley http://orcid.org/0000-0003-0337-406X

Irene Braithwaite http://orcid.org/0000-0001-5327-3027

\section{REFERENCES}

1 World Health Organization. Statement on the second meeting of the International health regulations (2005) emergency Committee regarding the outbreak of novel coronavirus (2019-nCoV), 2020 Available: https://www.who.int/news-room/detail/30-01-2020statement-on-the-second-meeting-of-the-international-healthregulations-(2005)-emergency-committee-regarding-the-outbreak-ofnovel-coronavirus-(2019-ncov)

2 New Zealand Minsitry of Health. COVID-19 - current cases, 2020. Available: https://www.health.govt.nz/our-work/diseases-andconditions/covid-19-novel-coronavirus/covid-19-current-situation/ covid-19-current-cases

3 New Zealand Government. COVID-19 alert system, 2020. Available: https:/covid19.govt.nz/government-actions/covid-19-alert-system/

4 Cetron M, Landwirth J. Public health and ethical considerations in planning for quarantine. Yale J Biol Med 2005;78:329-34.

5 Martini M, Gazzaniga V, Bragazzi NL, et al. The Spanish influenza pandemic: a lesson from history 100 years after 1918. J Prev Med Hyg 2019;60:E64-7.

6 Blavatnik School of Government. COVID-19: government response stringency index, March 21,2020, 2020. Available: https:// ourworldindata.org/grapher/covid-stringency-index?year=2020-0321
7 Pan A, Liu L, Wang C, et al. Association of public health interventions with the epidemiology of the COVID-19 outbreak in Wuhan, China. JAMA 2020;323:1915-23.

8 Imperial College COVID-19 Response Team. Report 13: estimating the number of infections and the impact of non-pharmaceutical interventions on COVID-19 in 11 European countries 2020.

9 Chaudhury A, Gaude GS, Hattiholi J. Effects of oral montelukast on airway function in acute asthma: a randomized trial. Lung India 2017;34:349-54.

10 Cousins S. New Zealand eliminates COVID-19. Lancet 2020;395:1474.

11 Harris PA, Taylor R, Thielke R, et al. Research electronic data capture (REDCap)--a metadata-driven methodology and workflow process for providing translational research informatics support. J Biomed Inform 2009;42:377-81. doi:10.1016/j.jbi.2008.08.010

12 New Zealand Government. Essential businesses and services at alert level 4, 2020. Available: https://covid19.govt.nz/businessesand-employees/businesses-and-services/essential-businesses-andservices/

13 New Zealand Government. At-risk people - who is at higher risk from coronavirus, 2020. Available: https://covid19.govt.nz/individuals-andhouseholds/health-and-wellbeing/at-risk-people/

14 Ministry of Health. HISO 10001:2017 ethnicity data protocols, 2017. Available: health.govt.nz

15 Health and Disability Ethics Committees. Operating procedures, 2020. Available: https://ethics.health.govt.nz/operating-procedures

16 Survey Monkey. Sample size calculator, 2020. Available: https:// www.surveymonkey.com/mp/sample-size-calculator/

17 New Zealand Ministry for Culture and Heritage. The 1918 influenza pandemic. New Zealand history, 2020. Available: https://nzhistory. govt.nz/culture/influenza-pandemic-1918

18 Wu Z, McGoogan JM. Characteristics of and important lessons from the coronavirus disease 2019 (COVID-19) outbreak in China. JAMA 2020;323:1239. doi:10.1001/jama.2020.2648

19 The Lancet. Reviving the US CDC. Lancet 2020;395:1521.

20 United Nations Department of Economic and Social Affairs. Household size \& composition, 2019, 2019. Available: https:// population.un.org/Household/\#/countries/4

21 Stats NZ Tatauranga Aotearoa. 2013 census QuickStats about families and households, 2014. Available: http://archive.stats.govt.nz/ Census/2013-census/profile-and-summary-reports/qstats-familieshouseholds/households.aspx

22 Wilson N, Barnard LT, Summers JA, et al. Differential mortality rates by ethnicity in 3 influenza pandemics over a century, New Zealand. Emerg Infect Dis 2012;18:71-7.

23 Verrall A, Norton K, Rooker S, et al. Hospitalizations for pandemic (H1N1) 2009 among Maori and Pacific Islanders, New Zealand. Emerg Infect Dis 2010;16:100-2.

24 King P, Cormack D, McLeod M. COVID-19 and Māori health - when equity is more than a word. Public Health Expert 2020 https://blogs. otago.ac.nz/pubhealthexpert/2020/04/10/covid-19-and-maorihealth-when-equity-is-more-than-a-word/

25 Ministry of Health. Analysis of household crowding based on census 2013 data, 2014. Available: https://www.health.govt.nz/publication/ analysis-household-crowding-based-census-2013-data

26 Armstrong S. Covid-19: virus and recession a devastating combination for Māori and Pasifika. RNZ, 2020. Available: https:// www.rnz.co.nz/news/in-depth/414499/covid-19-virus-and-recessiona-devastating-combination-for-maori-and-pasifika

27 Saleh A, Bista K. Examining factors impacting online survey response rates in educational research: perceptions of graduate students. J Multidiscip Eval 2017;13:63-74.

28 Kearns C, Baggott C, Harwood M, et al. Engaging Māori with qualitative healthcare research using an animated comic. Health Promot Int 2020:daaa111.

29 InternetNZ. State of the Internet 2017- the state of the Internet in New Zealand, 2017. Available: https://internetnz.nz/sites/default/ files/SOTI FINAL.pdf

30 NapoleanCat. Facebook users in New Zealand, 2020. Available: https://napoleoncat.com/stats/facebook-users-in-new_zealand/ 2020/03

31 Whitaker C, Stevelink S, Fear N. The use of Facebook in recruiting participants for health research purposes: a systematic review. $J$ Med Internet Res 2017;19:e290.

32 Thornton L, Batterham PJ, Fassnacht DB, et al. Recruiting for health, medical or psychosocial research using Facebook: systematic review. Internet Interv 2016;4:72-81.

33 Stats NZ Tatauranga Aotearoa. 2018 census population and dwelling counts, 2019. Available: https://www.stats.govt.nz/informationreleases/2018-census-population-and-dwelling-counts 
34 National Advisory Committee on Health and Disability (institution). Meeting the needs of people: Häpai te whänau Mo ake ake tonu, 2007. https://www.health.govt.nz/system/files/documents/ publications/meeting-needs-chronic-conditions-feb07.pdf

35 Financial Times. Cumulative confirmed cases of Covid-19 in United States, United Kingdom, New Zealand, Italy and Spain, 2020. Available: https://ig.ft.com/coronavirus-chart/?areas=usa\& areas $=\mathrm{gbr} \&$ areas $=\mathrm{nz} \mid \&$ areas $=$ ita\&areas $=\mathrm{esp} \&$ areasRegional $=$ usny\&areasRegional=usnj\&cumulative $=1 \& \operatorname{logScale}=1$ \&perMillion $=$ $0 \&$ values $=$ cases

36 Global Change Data Lab. Total and daily confirmed COVID-19 cases per million people, 2020. Available: https:// ourworldindata.org/grapher/total-daily-covid-cases-per-million? country $=\sim \mathrm{NZL}$ 